\title{
2-[p-(5,6-Methylenedioxy-2H-benzotriazol-2-yl)]phenethylamine as Fluorescence Derivatization Reagent for Carboxylic Acids in High Performance Liquid Chromatography
}

\author{
Shigeru Narita and Takayasu Kitagawa \\ Shionogi Research Laboratories, Shionogi \& Co., Ltd., Fukushima, Osaka 553, Japan
}

\begin{abstract}
2-[p-(5,6-Methylenedioxy-2H-benzotriazol-2-yl)]phenethylamine (MBPA; 1$)$ and two related compounds (2 and 3) were synthesized as highly sensitive fluorescence derivatization reagents for carboxylic acids. We investigated the fluorescence characteristics and the chromatographic behavior of their benzamide derivatives produced by the reaction with benzoic acid. Among them, MBPA was found to be the best reagent for use in high performance liquid chromatography (HPLC). Thus it was applied to the determination of ibupprofen in human serum. MBPA reacted with ibuprofen in the presence of 2-bromo-1-ethylpyridinium tetrafluoroborate to give the corresponding fluorescent amide at room temperature. Linear relationships were found between the peak areas and the concentrations of ibuprofen in the range of $5-100 \mathrm{ng} / \mathrm{ml}$ and $0.5-5 \mathrm{ng} / \mathrm{ml}$ with relative standard deviations of $7.49 \%$ and $15.02 \%$, respectively. The detection limit for ibuprofen in serum was $1.5 \mathrm{pg}$ per injection.
\end{abstract}

Keywords Fluorescence derivatization, 2-[p-(5,6-methylenedioxy-2H-benzotriazol-2-yl)]phenethylamine, high performance liquid chromatography, carboxylic acid, ibuprofen, labeling reagent

In a previous paper ${ }^{1}$, a new fluorescence derivatization reagent 2-( $p$-aminomethylphenyl)- $N, N$-dimethyl- $2 H$ benzotriazolyl-5-amine (AMDBA), for the determination of carboxylic acids by high performance liquid chromatography (HPLC) was reported. AMDBA is a highly sensitive reagent and reacts with several carboxylic acids in the presence of 2-bromo-1-ethylpyridinium tetrafluoroborate (BEPT) at room temperaure.

In the present work, we synthesized some triazole derivatives, $2-[p$-(5,6-methylenedioxy- $2 H$-benzotriazol-2-yl)]phenethylamine (MBPA; 1$), p-(5,6-$ methylenedioxy- $2 H$ benzotriazol-2-yl)benzylamine (MBBA; 2$)$ and $p-(5,6-$ dimethoxy-2 $H$-benzotriazol-2-yl)benzylamine (DBBA; 3) as even more sensitive fluorescence derivatization reagents for carboxylic acids in HPLC (Chart 1). The fluorescence characteristics and the chromatographic behavior of the benzamide derivatives of these reagents were investigated. MBPA was selected and applied to the determination of carboxylic acid in the biological sample. The highly sensitive HPLC method for ibuprofen in human serum was established.

\section{Experimental}

\section{Apparatus}

A Hitachi 650-60 fluorescence spectrophotometer was used for fluorescence measurements. All melting points were measured with a Yanagimoto micro melting point apparatus and were uncorrected.

HPLC apparatus: A Shimadzu LC-4A pump equipped with a Shimadzu RF-535 fluorescence HPLC mon-

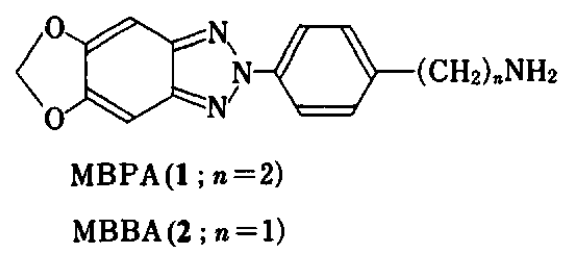<smiles>COc1cc2nn(-c3ccc(CN)cc3)nc2cc1OC</smiles> 
itor and a Rheodyne model 7125 injection valve with a $200 \mu \mathrm{l}$ sample loop were used. A NOVA PAK $\mathrm{C}_{18}$ (150×3.9 mm i.d.; Waters Assoc.) was used as an analytical column, in combination with a Nucleosil $5 \mathrm{C}_{18}$ (30×4.0 mm i.d.; Macherey-Nagel) as a guard column. A Shimadzu Chromatopac C-R2AX data processor was used for the data treatment.

HPLC conditions: $\mathrm{CH}_{3} \mathrm{CN}-\mathrm{H}_{2} \mathrm{O}$ mixture (13:10) was used as a mobile phase at a flow rate of $1.0 \mathrm{ml} / \mathrm{min}$.

\section{Reagents and materials}

Ibuprofen and human serum type $\mathrm{AB}$ were purchased from Sigma Chemical Co. and Flow Laboratories Inc., respectively. Bond Elut columns ( $\mathrm{Si}$ and $\mathrm{C}_{18}$ ) were purchased from Analytichem International. The other chemicals were of reagent grade.

\section{Synthesis of fluorescence derivatization reagents}

Reagent compounds were synthesized by the same method described previously. ${ }^{1}$

2-[p-(5,6-Methylenedioxy-2H-benzotriazol-2-yl)]phenethyl amine (MBPA; 1): $\quad N$-(p-Aminophenethyl)-2,2,2-trifluoroacetamide hydrochloride $(2.7 \mathrm{~g} ; 10 \mathrm{mmol})$ was diazotized and coupled with 3,4-methylenedioxyaniline $(1.4 \mathrm{~g} ; 10 \mathrm{mmol})$ by the usual manner. The resulting azo compound was recrystallized from DMF-MeOH as red needles; $\mathrm{mp} 165-166^{\circ} \mathrm{C}$. The azo compound $(2.5 \mathrm{~g}$; $6.6 \mathrm{mmol}$ ) was dissolved in pyridine $(40 \mathrm{ml})$ and an ammoniacal cupric sulfate solution $\left(10 \mathrm{~g}\right.$ of $\mathrm{CuSO}_{4} \cdot 5 \mathrm{H}_{2} \mathrm{O}$ and $5 \mathrm{~g}$ of $\mathrm{NH}_{4} \mathrm{Cl}$ were dissolved in $80 \mathrm{ml}$ of $\mathrm{H}_{2} \mathrm{O}$ and neutralized with $\mathrm{NaHCO}_{3}$ ) was added to the stirred pyridine solution. The reaction mixture was refluxed for $1 \mathrm{~h}$. After addition of $\mathrm{H}_{2} \mathrm{O}(200 \mathrm{ml})$, the precipitates were collected, washed with $1 \% \mathrm{NH}_{4} \mathrm{OH}$ and dissolved in pyridine $(30 \mathrm{ml}) .1 \mathrm{M} \mathrm{NaOH}(30 \mathrm{ml})$ was added to the pyridine solution. The solution was refluxed for $1 \mathrm{~h}$ and then poured into $\mathrm{H}_{2} \mathrm{O}(200 \mathrm{ml})$. The precipitates were collected, washed with $\mathrm{H}_{2} \mathrm{O}$ and recrystallized from $\mathrm{MeOH}$ to give MBPA as colorless needles (Table 1).
p-(5,6-Methylenedioxy-2H-benzotriazol-2-yl)benzylamine (MBBA; 2): MBBA was synthesized in the way described in the synthesis of MBPA. $N$ - $(p$-Aminobenzyl)-2,2,2-trifluoroacetamide was used instead of $\mathrm{N}$ ( $p$-aminophenethyl)-2,2,2-trifluoroacetamide hydrochloride. Recrystallization from $\mathrm{MeOH}$ gave MBBA as colorless needles (Table 1).

$p$-(5,6-Dimethoxy-2 $H$-benzotriazol-2-yl)benzylamine (DBBA; 3): DBBA was synthesized in the same way as described for the synthesis of MBPA. 3,4-Dimethoxyaniline and $N$ - ( $p$-aminobenzyl)-2,2,2-trifluoroacetamide were used instead of 3,4-methylenedioxyaniline and $N$-( $p$-aminophenethyl)-2,2,2-trifluoroacetamide hydrochloride, respectively. Recrystallization from EtOH gave DBBA as colorless needles (Table 1).

Preparation of the fluorescent amide derivatives (1a-3a)

Benzoic acid $(0.5 \mathrm{mmol})$ was dissolved in $\mathrm{CH}_{2} \mathrm{Cl}_{2}$ $(10 \mathrm{ml})$. After addition of BEPT $(150 \mathrm{mg})$, 9-methyl3,4-dihydro-2 $H$-pyrido[1,2-a]pyrimidin-2-one (MDPP; $200 \mathrm{mg}$ ) and the fluorescence derivatization reagent (MBPA, MBBA or DBBA; $0.5 \mathrm{mmol}$ ), the reaction mixture was stirred for $30 \mathrm{~min}$ at room temperature. After filtration, the filtrate was concentrated in vacuo. The residue was dissolved in $\mathrm{CHCl}_{3}(2 \mathrm{ml})$ and chromatographed on a silica gel column with $\mathrm{CHCl}_{3}$. The eluate was concentrated in vacuo and the residue was recrystallized from $\mathrm{CHCl}_{3}-\mathrm{MeOH}$ to give the corresponding amide (Table 1).

\section{Derivatization procedure}

A serum sample $(1 \mathrm{ml})$ was acidified with $1 \mathrm{M} \mathrm{HCl}$ $(0.1 \mathrm{ml})$ and then passed through a Bond Elut $\left(\mathrm{C}_{18}\right)$ column. After successive washings with $\mathrm{H}_{2} \mathrm{O}(10 \mathrm{ml})$ and $50 \% \mathrm{MeOH}(6 \mathrm{ml})$, the desired fraction was eluted with $85 \% \mathrm{MeOH}(2 \mathrm{ml})$. After the eluate was dried under a stream of nitrogen, the residue was dissolved in $\mathrm{CH}_{3} \mathrm{CN}(0.5 \mathrm{ml})$. To this solution, $50 \mu \mathrm{l}$ each of BEPT (3.7 mM), MDPP (2.7 mM) and MBPA (3.7 mM) solutions in $\mathrm{CH}_{3} \mathrm{CN}$ were added. After mixing for $10 \mathrm{~s}$, the mixture was allowed to stand for $90 \mathrm{~min}$ at room

Table 1 Physicochemical and analytical data

\begin{tabular}{|c|c|c|c|c|c|c|c|}
\hline \multirow{2}{*}{$\begin{array}{c}\text { Compd. } \\
\text { No. }\end{array}$} & \multirow{2}{*}{ Appearance } & \multirow{2}{*}{ Yield, \% } & \multirow{2}{*}{$\mathrm{mp} /{ }^{\circ} \mathrm{C}$} & \multirow{2}{*}{ Formula } & \multicolumn{3}{|c|}{ Analysis, \%: Calcd/Found } \\
\hline & & & & & C & $\mathbf{H}$ & $\mathbf{N}$ \\
\hline \multirow[t]{2}{*}{1} & colorless needles & 55.6 & $145-147$ & $\mathrm{C}_{15} \mathrm{H}_{14} \mathrm{~N}_{4} \mathrm{O}_{2} \cdot 1 / 4 \mathrm{H}_{2} \mathrm{O}$ & 62.82 & 5.10 & 19.54 \\
\hline & & & & & 62.66 & 5.21 & 19.55 \\
\hline \multirow[t]{2}{*}{2} & colorless needles & 53.7 & $202-203$ & $\mathrm{C}_{14} \mathrm{H}_{12} \mathrm{~N}_{4} \mathrm{O}_{2} \cdot 1 / 4 \mathrm{H}_{2} \mathrm{O}$ & 61.64 & 4.62 & 20.54 \\
\hline & & & & & 61.86 & 4.64 & 20.53 \\
\hline \multirow[t]{2}{*}{3} & colorless needles & 45.7 & $155-156$ & $\mathrm{C}_{15} \mathrm{H}_{16} \mathrm{~N}_{4} \mathrm{O}_{2} \cdot 1 / 2 \mathrm{H}_{2} \mathrm{O}$ & 61.42 & 5.84 & 19.10 \\
\hline & & & & & 61.54 & 5.83 & 19.05 \\
\hline \multirow[t]{2}{*}{ 1a } & colorless needles & 65.9 & $262-264$ & $\mathrm{C}_{22} \mathrm{H}_{18} \mathrm{~N}_{4} \mathrm{O}_{3} \cdot 1 / 4 \mathrm{H}_{2} \mathrm{O}$ & 67.60 & 4.77 & 14.33 \\
\hline & & & & & 67.72 & 4.82 & 14.31 \\
\hline \multirow[t]{2}{*}{$2 a$} & colorless needles & 56.3 & $261-262$ & $\mathrm{C}_{21} \mathrm{H}_{16} \mathrm{~N}_{4} \mathrm{O}_{3}$ & 67.73 & 4.33 & 15.05 \\
\hline & & & & & 67.67 & 4.35 & 14.92 \\
\hline \multirow[t]{2}{*}{$3 \mathbf{a}$} & colorless needles & 56.3 & $225-226$ & $\mathrm{C}_{22} \mathrm{H}_{20} \mathrm{~N}_{4} \mathrm{O}_{3}$ & 68.03 & 5.19 & 14.42 \\
\hline & & & & & 67.95 & 5.30 & 14.48 \\
\hline
\end{tabular}


temperature. Then, $0.5 \mathrm{ml}$ of the reaction mixture was passed through a Bond Elut (Si) column and eluted with $1.5 \mathrm{ml}$ of $\mathrm{CH}_{3} \mathrm{CN}$. The eluate was diluted with $\mathrm{CH}_{3} \mathrm{CN}$ to make $2.5 \mathrm{ml}$. The resulting solution $(20 \mu \mathrm{l})$ was injected into the chromatograph.

\section{Results and Discussion}

\section{Evaluation of fluorescence derivatization reagents}

In order to select the fluorescence derivatization reagent for carboxylic acids, the fluorescence characteristics of the benzamide derivatives of the reagents, $1 \mathrm{a}-$ 3a, were measured in $\mathrm{CH}_{3} \mathrm{CN}$ solution. As shown in Table 2, the fluorescence properties of the derivatives were almost the same. The excitation and emission maxima of these derivatives were much shorter than that of AMDBA $\left(\lambda_{\text {ex }} ; 390 \mathrm{~nm}, \lambda_{\mathrm{em}} ; 488 \mathrm{~nm}\right)$. Figure 1 shows the fluorescence spectra of $1 \mathrm{a}$ in $\mathrm{CH}_{3} \mathrm{CN}$.

The effect of $\mathrm{H}_{2} \mathrm{O}$ concentration on the fluorescence intensity was examined. As shown in Fig. 2, the fluorescence intensity of $1 \mathrm{a}$ in the aqueous $\mathrm{CH}_{3} \mathrm{CN}$ was almost constant at $\mathrm{H}_{2} \mathrm{O}$ concentrations of $0-50 \%(\mathrm{v} / \mathrm{v})$,

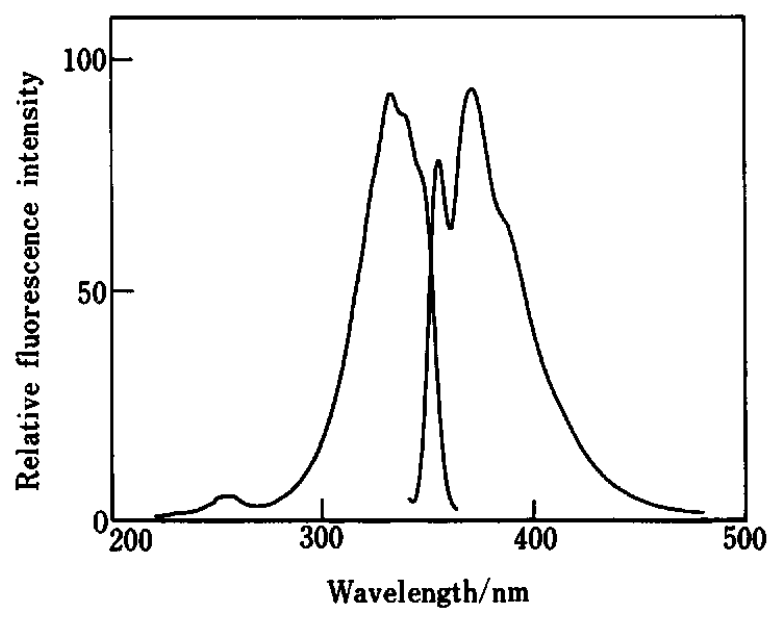

Fig. 1 Excitation and emission spectra of compound 1a $\left(2 \times 10^{-7} \mathrm{M}\right)$ in $\mathrm{CH}_{3} \mathrm{CN}$. but was slightly decreased in proportion to the $\mathrm{H}_{2} \mathrm{O}$ concentration over $50 \% \mathrm{H}_{2} \mathrm{O}$; at $90 \% \mathrm{H}_{2} \mathrm{O}$, the intensity was about $85 \%$ of the maximum value. $2 a$ and $3 a$ showed the same profiles.

The chromatographic behavior, retention time and detection limit of the amides were also investigated (Table 2). The detection limits of three amides were $0.5 \mathrm{fmol}$ per injection. It was thus found that the intensities of the amides derivatized with reagents synthesized in this work were 30 times that with AMDBA (detection limit; $15 \mathrm{fmol}$ ) and that these reagents were one of the most sensitive reagents for carboxylic acids. The retention time of $1 \mathrm{a}$ was larger than those of $2 a$ and $3 a$, indicating that MBPA was more favorable for the separation of the biological samples than MBBA and DBBA. Therefore, MBPA was selected for further investigation to develop an analytical procedure for ibuprofen in human serum.

Conditions for the determination of ibuprofen in human serum

Clean-up of ibuprofen in serum sample. Several cleanup procedures for the determination of ibuprofen

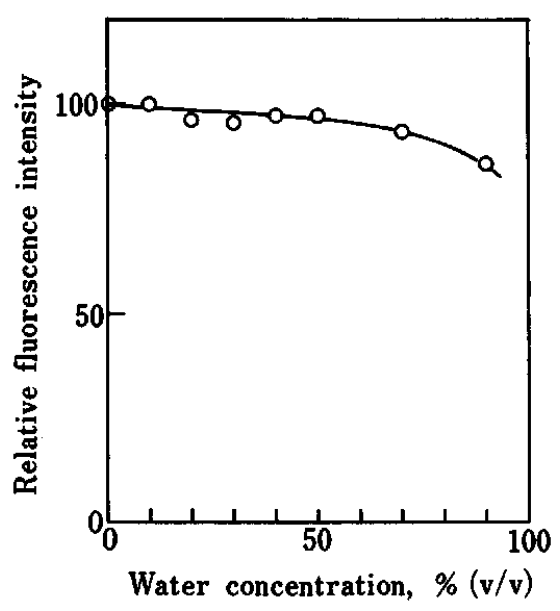

Fig. 2 Effect of water concentration on the fluorescence intensity of compound $1 \mathrm{a}\left(2 \times 10^{-7} \mathrm{M}\right)$ in aqueous $\mathrm{CH}_{3} \mathrm{CN}$.

Table 2 Fluorescence characteristics and chromatographic behavior of triazole derivatives (1a-3a)

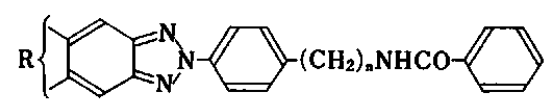

\begin{tabular}{|c|c|c|c|c|c|c|c|}
\hline \multirow{2}{*}{$\begin{array}{c}\text { Compd. } \\
\text { No. }\end{array}$} & \multirow{2}{*}{$\mathbf{R}$} & \multirow{2}{*}{$n$} & \multicolumn{3}{|c|}{ Fluorescence characteristics ${ }^{\mathbf{a}}$} & \multicolumn{2}{|c|}{ Chromatographic behavior ${ }^{b}$} \\
\hline & & & $\lambda_{\text {ex }} / \mathrm{nm}$ & $\lambda_{\mathrm{em}} / \mathrm{nm}$ & RFI, \% & $R_{\mathbf{t}} / \min$ & (fmol/inj.) \\
\hline 1a & 5,6-methylenedioxy & 2 & 333 & 372 & 100 & 8.9 & 0.5 \\
\hline 2a & 5,6-methylenedioxy & 1 & 333 & 372 & 106 & 7.8 & 0.5 \\
\hline $3 a$ & 5,6-dimethoxy & 1 & 332 & 369 & 104 & 6.3 & 0.5 \\
\hline
\end{tabular}

a. Observed in $\mathrm{CH}_{3} \mathrm{CN}$ solution. b. HPLC conditions: column, Nucleosil $5 \mathrm{C}_{18}(150 \times 4.6 \mathrm{~mm}$ i.d.); guard column, Nucleosil $5 \mathrm{C}_{18}\left(30 \times 4.0 \mathrm{~mm}\right.$ i.d.); mobile phase, $\mathrm{CH}_{3} \mathrm{CN}: \mathrm{H}_{2} \mathrm{O}=4: 3$; flow rate, $1.0 \mathrm{ml} / \mathrm{min}$. c. Detection limit $S / N=5$. 


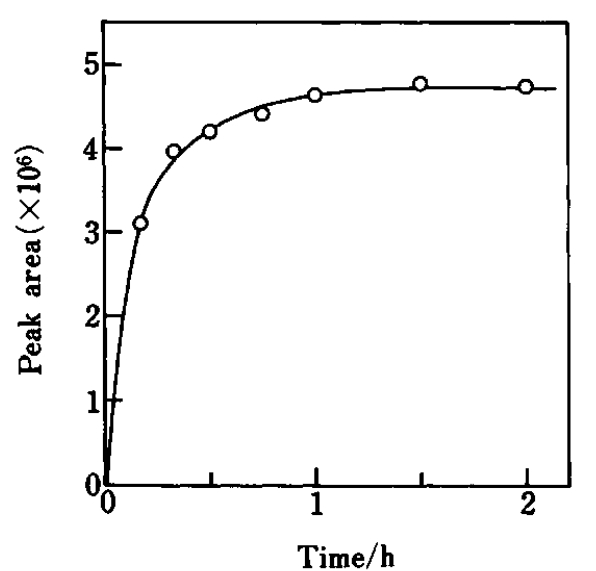

Fig. 3 Effect of reaction time on the peak area. Serum samples spiked with $20 \mathrm{ng}$ of ibuprofen were treated according to the derivatization procedure but for various periods.

in serum have been reported. ${ }^{2-5}$ The extraction with the organic solvent is commonly used prior to HPLC. We first attempted the extraction of ibuprofen with isooctane-isopropanol mixture. ${ }^{2}$ But many endogenous substances which could react with MBPA were also extracted, with the result that numerous interfering peaks were found on the chromatogram. Then the solid phase extraction was examined. A Bond Elut $\mathrm{C}_{18}$ column was employed in our work. The serum sample was acidified with $1 \mathrm{M} \mathrm{HCl}$ and was passed through the column. Co-existing polar substances were removed with $\mathrm{H}_{2} \mathrm{O}$ and $50 \% \mathrm{MeOH}$, while ibuprofen was adsorbed on the column and eluted with $85 \% \mathrm{MeOH}$. The recovery of this procedure was quantitative. The eluate was evaporated under the stream of nitrogen followed by the derivatization procedure.

Derivatization of ibuprofen with MBPA. Derivatization conditions in this work were the same as those described in our previous paper, except for reaction time. Although the reaction of MBPA with authentic ibuprofen was completed within 30 min to give the corresponding amide, it required a longer time to obtain the sufficient yield when conducted with serum sample. Figure 3 shows the effect of time on the reaction. The maximum and constant peak areas were attained after $1 \mathrm{~h}$.

Excess MBPA was removed from the reaction mixture by a simple pretreatment method, using a Bond Elut Si column, established previously. The typical chromatogram obtained by the assay procedure is shown in Fig. 4. No interfering peaks were detected at the retention time of ibuprofen under the chromatographic conditions.

\section{Evaluation of the assay procedure}

The linearity of the peak area with the concentration

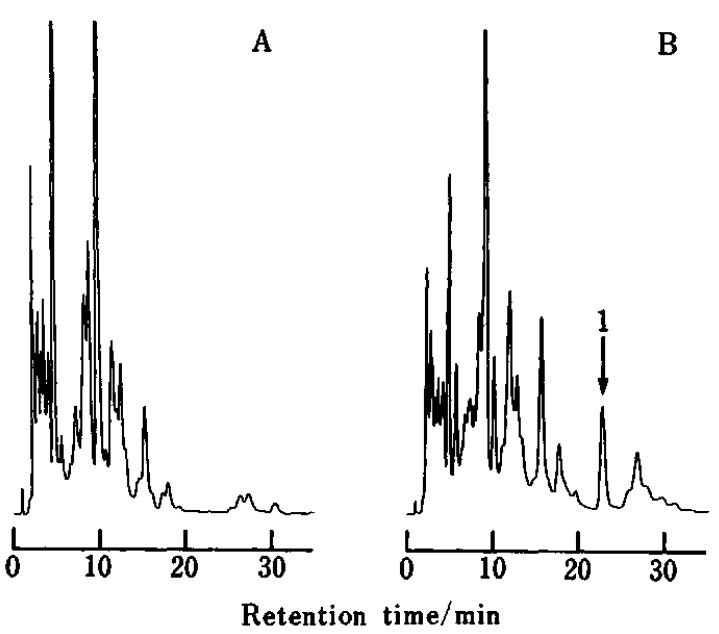

Fig. 4 Chromatograms of serum samples obtained after derivatization with MBPA. A, serum blank; B; serum sample spiked with $20 \mathrm{ng}$ of ibuprofen; 1 : amide derived from MBPA and ibuprofen.

of ibuprofen was examined. Calibration curves constructed with serum samples spiked with 5-100 and 0.5-5 ng of ibuprofen showed the linearity with relative standard deviations of $7.49 \%$ and $15.02 \%$, respectively. The recovery of ibuprofen through the assay was $100.6 \%$. The assay was reproducible and a good precision was obtained by the repeated assay of serum samples spiked with $20 \mathrm{ng}$ of ibuprofen with relative standard deviation, $2.14 \%(n=10)$. The detection limit for ibuprofen in serum sample was $1.5 \mathrm{pg}$ per injection. The assay procedure established in this work showed a high sensitivity and sufficient reliability.

The new fluorescence derivatization reagent, MBPA, was found to be a highly sensitive reagent and should be useful for the determination of carboxylic acids in the small amounts of biological samples.

\section{References}

1. S. Narita and T. Kitagawa, Chem. Pharm. Bull., 37, in press.

2. H. Litowitz, L. Olanoff and C. L. Hoppel, J. Chromatogr., 311, 443 (1984).

3. D. Pitre and M. Grandi, J. Chromatogr., 170, 278 (1978).

4. G. L. Kearns and J. T. Wilson, J. Chromatogr., 226, 183 (1981).

5. J. H. G. Jonkman, R. Schoenmaker, A. H. Holtkamp and J. Hempenius, J. Pharm. Biomed. Anal., 3, 433 (1985).

(Received September 30, 1988)

(Accepted November 9, 1988) 